\title{
Learner Perspective of Li Use in L2 Collaborative Writing: An Emic View
}

\author{
Sathuvalli Mohanraj \\ Uma Maheshwari Chimirala
}

The English and Foreign Languages University, Hyderabad, India

\begin{abstract}
Studies investigating the use of L1 in the L2 classroom space have done so from three viewpoints: the teacher's use of L1, the learner's perspective about the teacher's use of L1 and the learner's use of L1 in L2 writing as the learners participate in think aloud protocols or in collaborative writing. All three perspectives present the etic view of the act of using the L1 and report mixed and sometimes contradictory findings of what learners' feel about the role L1 can play in the L2 learning context. Rarely have studies explored the learner's perspective of their own use of L1 after a collaborative writing activity. By and large the image that emerges from the learners' perspective is that the L1 is useful but thatit could be a blockade and a hindrance in acquiring the L2. We ask if this view would still persist if the learners were to bank on their L1 capabilities rather than comment on their Teacher's Bi/Multilingual capabilities. Therefore, we interviewed 24, class 8, beginner level dyad writers (12 pairs) in a Zillah Parishad High School after they had collaboratively created three texts together. Qualitative analysis of the dyad interviews suggests that the learner's need to be 'allowed' to explore their language capabilities before they realize the pedagogic potentiality of the L1 and decide on whether L1 is useful or otherwise.
\end{abstract}

Key words: L1 use in L2 collaborative writing; learner's perspective; emic view

\section{INTRODUCTION: TO USE OR NOT TO USE?}

The debate over the use of the learner's mother tongue in the L2 classroom has been the bone of contention between its advocates and its opponents of now the inconclusive and contradictory research findings have not been 


\section{$2 \mid$ ELT Worldwide Vol. 1 No. 1}

persuasive either way. The debate is equally charged. Proponents for the use of L1 in L2 classroom argue that using L1 helps in the following:

1. Busting anxiety (Harboud, 1992)

2. Opening the class to English, improving retention of content, fostering progress and reducing cognitive load (Auerbach, 2000).

3. Providing for egalitarian opportunity to access and attainment (Mohanty, 2009).

4. Cognitively allowing the learner to make sense of the concept and the language (Cook, 2001).

5. Acknowledging their social, cognitive, cultural and bi/multilingual capabilities and identities (Canagarajah, 2012).

Arguments against the use of L1 in the class are founded on the premises that: 1). using L1 indicates that opportunity of 'adequate' input is deprived and that learners do not get opportunity to use L2 (Krashen, 1985); 2). learners need to be 'pushed' to produce L2; using L1 would be seen as an easy and soft option (Hawks, 2001); 3). may be a sign of insufficiently trained teacher (Promodue, 2000) and that teachers may over use (Turnbull, 2001). Clearly, arguments against L1 assume that 'Target language exposure' is the causal factor for L2 acquisition while those in favor of L1 use humanistic, affective and socio-cognitive arguments. But the larger question that is often left out is if the L1 is seen as useful in learning then whose use of L1 matters? The teachers or the learners? Literature foregrounds the teacher's use since the assumption is that teaching augments learning; however, learning is, we believe, a 'learner's affair' and that teaching needs to provide the support systems that go beyond L2 acquisition to enabling participation in both the processes and the products of learning (Sfard, 1998).

Though an extensive body of research exists on the issue of the L1 in the L2 classroom space, we notice a bias for the L2 in the very conceptualization of these studies. Use of L1 has been predominantly investigated from the teacher's use perspective in various contexts while the learner is restricted to an observer's role in voicing his perceptions of the teacher's use of L1 in the classroom space. Often these studies are set in 'assumed' monolingual language learning context, teaching methodologies and assessment frameworks with explicit or implicit views of the L1 as an 'outsider' in the classroom space. Evidently, explorations in such contexts will result in mixed and contradictory findings regarding whether, when and why learners find their L1 useful. Research in this area is predominantly ethics i.e. the objective researcher's version of the investigation is projected while the learner's voices though accounted in the data analysis remains peripheral. This study places the learner in the center-stage and thus contributes to the literature on the learner's view of his mother tongue, albeit with a different argument and methodology. It aims to present an emic perspective the 
learner's use of L1 not based on the teachers' use of L1 but based on their own use of L1 in their text construction processes through collaborative writing. In the next section, a brief background to the literature on the 'use of L1' in the classroom space is presented. It has been examined from two overt and one covert viewpoint.

\section{LITERATURE REVIEW: WHOSE L1 USE MATTERS?}

As noted above, the use of L1 in the L2 classroom has been investigated from the teacher's perspective, the learner's opinion on the teacher's use of L1 and the ethic perspective on learner's use of L1 (in L2 writing). Since our interest happens to be the learner and her opinion on L1 use, we touch upon the teacher's use of L1 very briefly but attempt to examine the learner's perspective in detail.

\section{Teacher's Use}

Teacher's use of L1 has been examined extensively through questions such as how much of L1 is used in terms of percentages and utterances (Al-Hinai, 2006), for what purposes do the teachers use the L1 (Duff \& Polio, 1990; Macaro, 2001), why do they use L1 (Harboud, 1992), what are their reflections on their own L1 utterances (Polio \& Duff, 1994) and what purposes does the switching serve. Teachers reported using the L1 for:

a. Eliciting language knowledge, checking comprehension, giving instructions, task instructions, glossing, humor, contrasting and for commenting (De La Campa\&Nassaji, 2009);

b. Engaging in functional translation as against word-to-word translation (Danchev, 1982 cited in Cook, 2001);

c. Explaining meaning, summarizing, classroom management (Pathak, 2005; Atkinson, 1987); and

d. 'Bonding purposes' as a communicational strategy (Al Hinai, 2006).

Research concludes that factors such as institutional L2 policy, context of study and teacher factors correlate with the teachers' use of L1 (RolinIanziti\&Varshney, 2009).

\section{Learner's Perspective on Teacher's Use of L1}

Studies from this perspective have asked their learners to either give their opinion about their teacher's use of L1 and/or to think about how their L1 can help in L2 learning. Methodologically open ended and/or forced option questionnaires or interviews were used. Either way L1 is seen as an intruder in the L2 classroom space. Seldom were learners asked to go 'meta' about their own use of L1 to arrive at an opinion. 
Macaro's (1997) investigation of his high school learners' opinions about their teachers' English-only practices revealed a divergence. While a small 'able' group of learners did not mind the 'use only English' attitude, a majority wanted their L1 to be used for 'knowing the exact meaning of a word' (p.103). Al-Hinai's learners in a technical institute, brainstormed about the uses L1 'can serve' in an L2 classroom and felt that without L1 translations abstract concepts and terms would remain incomprehensible. Like Macaro (1997), only a small number of learners felt that their teacher should use only L2 and absolutely no L1.

Mahmoudi (2011) investigated the amount of L1 use and the learner's perception of the L1 use in an Iranian context. She finds that the learners preferred an L2 only context and that any L1 use by the teachers was seen as de-motivating. Learners in the case of Schweer's study (1999, p.7) reported that the use of L1 reduced anxiety and helped them feel "less tense and less lost" however excessive use was not appreciated. Similarly, Nazarey (2008) finds that his university students in Tehran were reluctant to any use L1 in L2 classes on the grounds that "any minute of using L1 will diminish a minute of their exposure to L2".

Rolin-Ianziti\&Varshney (2009) examined learner perception of teacher's use of TL and L1 based on Ellis (1988) categorization of teacher's use of L1 as being medium-oriented use (i.e. used to teach grammar or vocabulary) and Framework-oriented use (i.e. used to give instructions about the activity). They report a positive yet conflicting trend in their respondents where the need for both the languages is simultaneously felt and negated. The learners in this study felt that the L1 is important especially for gaining explicit knowledge of linguistic features but at the same time opine that it "reduces the chances of learning L2", "becomes an escape route for poor students and stunts learning in better students" (p.263). The study concludes that while L1 use reduces anxiety it could also be demotivating.

Clearly, learner attitudinal tendency to their teacher's use of L1 appears to be dependent on learner-related factors such as their proficiency, the instructional contexts; teacher related variables such as teaching method, belief about the L1, its applicability and L2 exclusivity and a host of institutional and socio-economic factors (Macaro, 2001). It reflects the dominant notion that maximal exposure to target language is beneficial - a view that relegates the learner's L1 resources to the background. As the review highlights, it is the teacher and the teacher's use of L1 (or L2) that matters, because teacher is center-stage despite some studies oriented to the CLT methodology. This viewof L1 is restricted to its status as just the learners' lingua franca and does not go beyond that to envisage it as a potential tool that learners can wield to their advantage in their learning processes. Throughout the investigation, a theoretical orientation to 'imitate' 
the naturalistic first language learning context is noticed, i.e. an assumption that second language learning needs to proceed like the first language learning without recourse to the other language in the learners' mind. However, research from bilingual education, bilingual processing and increasing evidence from multilingual education contexts and experiments report a clear cognitive benefit that the learner' L1 gives to learning L2, or $\mathrm{Ln}$ for that matter, and that they 'surreptiously' use L1 in their minds (Canagarajah, 2012).

\section{Learner's Use of L1 (Specifically in L2 Writing)}

Research in L2 writing has consistently found that writing for a bi/multilingual is a bi/multilingual activity where the 'other' languages that the learners possess in their repertoire are activated and in myriad ways support and contribute to the complex thinking processes involved in 'L2 writing' (Grosjean, 1989: Cook, 2001; Cummins, 2007). Findings report that the use of L1 in L2 writing occurs across proficiency levels (Qi, 1998; Wang \& Wen, 2003), writing abilities (Schoonen et al., 2003; Pennington \& So 1993), varying extents of prior writing instruction in L1 and/ or L2 (Kobayashi \&Rinnert, 2009), varying periods of 'naturalistic' exposure to L2 in countries where L2 is spoken as the L1 (Sasaki, 2009) and varying levels of task complexity (Wang, 2002; Qi, 1998: Murphy et al., 2010). Research speculates that this switch to the $\mathrm{L} 1$ is the outcome of a nexus of variables that involve writer-based, task-based and the language capability-based variables.

L1 is used for different purposes in each stage of the writing process namely Planning, Transcription and Revision. More specifically, the role that L1 plays in the problem solving and lexical searches is evidence for the strategic ways in which learners draw on their L1 capabilities and the strategic cognitive support it renders in problem solving (Chimirala, 2013).

Learner use of L1 in L2 collaborative writing has been examinedeither from the SLA perspective or from the SCT perspective. In the SLA perspective the focus of the interactions in the L1 is measured as Language Related Episode (LREs) as syntactic, lexical, morphological or mechanical LREs and whether the 'linguistic focus' can be diachronically retained (Swain \&Lapkin, 1998; De Collina\& Mayo, 2009; Storch\&Aldosari, 2010). From the SCT perspective, the L1 is seen as the problem-solving inner speech that occurs during a collaborative task. It is seenas evidence of the higher psychological processes. Through this perspective "language is a psychological tool that mediates the appropriation of the higher mental capacities" (Gutierrez, 2000) and the L1 becomes a prime semiotic and mediational tool. The use of L1 while engaged in task execution serves two immediate functions: task accomplishment and self-regulation for task 
6| ELT Worldwide Vol. 1 No. 1

navigation on the affective and cognitive plane (Anton \&DiCamilla 1998; Wells, 1998), while at the same time it goes beyond the existing activity to augment and nurture cognitive capabilities (Rogoff, 1990). Both the perspectives are experimental in nature as they investigate the impact of task-related, learner-related and writer-ability based variables on the nature of interactions and how the L1 is drawn.

In short, through this brief review and introduction, the following aspects become clear.

a. Arguments for the use of L1 are based on social, cognitive and affective factors; while the ones opposing the use of L1 are based on the assumption that learning requires maximal exposure to the target language and teacher competence.

b. One view of the L1 does not go beyond seeing it as a linguistic tool for comparing the target linguistic features and as a lingua franca.

c. It is the teacher's use of L1 that matters since the assumption is that learning can be 'orchestrated' by teachers and teaching.

d. An assumption that learners' will acquire the L2 through the teacher's use of L1 is in place - a narrow conception of learning as accumulation of knowledge rather than participation and in creation of knowledge (Sfard, 1998; Bereiter\&Scardamalia, 2006)

e. The teacher's bi/multilingual capabilities are legitimized to a certain extent but the learner's use of L1 is 'blasphemy' in an L2 classroom space.

f. L2 learning is assumed to proceed in the way that L1 is acquired; hence, the learner's use of L1 is seen as a block to L2 learning.

g. A narrow view of the languages in the mind as being separate is construed since overt and covert efforts to keep the two languages separate are in practice.

\section{Arriving at the Focus of the Study}

The review of previous research has taken the teacher's use of L1 as the trigger point for examining the way the L1 is perceived, but what of the myriad ways in which the learners use their L1 in L2 writing research? A study that explores the learner view of the way he/she used the L1 in an activity and their experience with it, to the best of our knowledge, has not been attempted. So drawing on the three sets of reviews on the use of L1, we are interested in exploring a more emic view of L1 use, where the learners use their L1 for a collaborative text construction and then reflect on their experience. Therefore the question we ask is: What would the learner's perception of his $L 1$ be if he were to reflect on his own LI use in a collaborative text construction activity in the classroom space?

\section{METHOD}


This study is a part of our doctoral research where we explored the nature of L1 support for L2 collaborative writing. Therefore, the data collected and analyzed in this paper come from a larger corpus of data. That is why the entire chapter of literature review is incorporated unnecessarily long. In the wider study, 24 participants arranged into 12 pairs collaboratively wrote 3 texts andin the post collaborative sessions participated in an interview. The present study draws on the interview transcript in order to understand their version of the use of L1.

\section{Participant}

In this study, 24 Class VIII participants from a government-run Zillah Parishad High School participated. These students came from poor home literacy environments and belonged to families of low socio-economic status. They had no writing instruction either in their L1 or their L2 and all the writing that the participants did was copied either from the black board or from the guides.

\section{Data Collection and Analysis Procedures}

The larger study used data collected in multiple modes such as collaborative dialogues, written texts and post-collaborative pair interviews. For this paper, we examine the post collaborative writing pair interviews. Openended questions that probed learner's perceptions of various aspects of collaborative writing were designed (Appendix 1). We used a semistructured format, as we were open to other issues that learners might point out in their responses. Therefore, we suited the interviews according to the pair being interviewed. So, we changed the order of the initial set of questions, picked up on the leads that the dyads gave and probed further. The interview audio files were transcribed and then analyzed qualitatively.

Following the principles of grounded enquiry, we searched for larger themes in these interview transcripts. Once the themes were identified, we looked for critical events and viewpoints that could reflect the learner's awareness of an aspect. Critical events are "highly charged moments that have an enormous potential for personal change and development" (Woods, 1993p.1; Wragg, 1994). The focus of this paper is on the dyad's perceptions of their L1 use in L2 collaborative writing. Correspondingly, two major themes evolved: (1) Dyad views of their L1 use in L2 collaborative writing, and (2) L1 use for L2 learning.

\section{RESULTS}

During the collaborative text construction, L1was used extensively. However, we wanted to know what, why and how the learners reported 
8| ELT Worldwide Vol. 1 No. 1

about the language aspect of collaboration? What language did they use? Why? Whether they reported that it aided in text construction? Correspondingly, the presentation of the results focuses on the two themes that evolved and the critical events presented here that support the interpretation.

\section{Dyad views on $\mathrm{L} 1$ use in $\mathrm{L} 2$ collaborative writing}

\section{L1 as the medium of communicating}

1. P: I have no other language to use except Telugu. My mother tongue is Urdu but Sudhakar does not know Urdu.. Maybe he knows a little but that is not enough so we both used Telugu only. And if it was not Telugu then we would not be able to write only. If you say to use only English to discuss then... what will we talk - nothing. May be we'll try but I know we will not be able to do anything at all.

2. R: Urdu is my mother tongue and Arun wanted to speak in Hindi. I am very good in Hindi. I get the first mark in exams. So we used Hindi.

3. A: for me Telugu is like my mother tongue so I already know it well. In school I am learning English and want to learn Hindi .... so we decided to use Hindi. R has no problem

There was unanimity in the opinion that the L1 was language for communicating with the partner throughout. However, in excerpt 2 and 3 we find that the choice of language is a negotiated one. The L1 clearly served as lingua franca for most of them except two pairs who chose other languages they had in their repertoire to mediate their text creation processes. Which language to use was a choice exercised based on the interlocutor or was based on a 'need to improve' rather than convenience.

\section{L1 use and task difficulty}

4. P: .... The park picture was very easy but the $K-22$ B task (Task $C 2$ ) was very difficult to understand. I had to explain to $S$ what the picture is. He was calling it a park... so it is wrong to say I used Telugu only to Communicate with my partner. I think Telugu is like this pencil to write. Without it, you can't write. Without Telugu, you can't finish the text. If you ask how our L1 was used in C1 and C2, I may not be able to tell clearly, but I know on the park task, I did not explain much but on the other two task, we argued a lot....about points, words to use, why, organization of the text-points, understanding the task and the task prompts ....

Dyads felt that their use of L1 was dependent on the writing task they were attempting. Reflecting on the way they used their L1 for communicating and for writing the text in L2, in Excerpt 4, learners were aware that they had not used and had depended on the L1 in the same way in writing each of the 
three tasks. The notion that learners would use their L1 differently depending on different tasks was something that was reflected upon when the learners were asked about it during the interviews. As $\mathrm{P}$ put it in his comparison with a pencil, the mother tongue is a tool used for a host of activities. The language that was preferred for socialization gradually became an academic tool wielded to complete the task at hand. Concrete ways in which the L1 had been used were not clearly enumerated by the participants, but a reflective stance that the L1 was not used identically during different tasks is evident when P said that during two of the tasks they had to negotiate "a lot....about points, words to use, why, organization of the text-points".

\section{L1 use and Error focus}

5. B: .... we focused on mistakes... in L1 we don't normally have tense errors... so like calculation we would do in L2. Then we would try the idea out in L1 first and then write to L2 and then back to L2. The same idea has to evolve. Otherwise, we'll try again now with the part where we think there is an error.

A common theme during discussions was 'mistakes and errors'. 8 out of the 12 pairs included error focus as its object of discussion. Excerpt 5 shows the dyad clearly voicing his lock-step error tackling strategy. He took a tense error as an example to point out that they used their L2 to solve it like 'calculations' but they did not stop there. The idea being transcribed was uttered as a pre-text in L1, transcribed in L2 and then back translated into L1 to check for appropriateness at the concept level and at the text level. L1 translation and back translation are two strategical modalities used for assessing the pre-text and the transcribed text.

\section{L1 use and Procedural Knowledge}

6. B: ...is there continuity in the paragraph? Nothing is suddenly written... we saw that very carefully. If we did not use LI then asking, telling and discussing about what we felt was wrong would have been impossible and thus we would not have learnt anything from our partners.

7. B: We discussed about whether the word we used is right, what structures to use, why to use. How to combine points also. Kwould always say that we should combine points, how and why. So we would discuss which points and how to combine points. I learnt that from her.

As $R$ puts it, what one of the writers did not know became the trigger of their discussion. Blocks and lack of automaticity in the production of the text production and the text transcription process created the need for discussion on very specific aspects that is fine-tuned to their task-specific needs. The focus was not restricted to declarative aspects of knowledge. In excerpts 6 and 7 the dyads make it explicit that procedural focus was also an integral 
10| ELT Worldwide Vol. 1 No. 1

part of the discussion when she talks of combining points. It is not just a discussion about which connector to use, but also why the two points have to be combined at all, how it is done and how it impacts the text. These are the issues that add a procedural advantage to learning and eventual to performance.

\section{L1 use in word Searches}

8. N: ... it is easy to get a word in Telugu but not in English. So we would try for other words in Telugu and then come to English to quickly get a word.

9. P: ....we always have problem with words. What word to write for this thing? We first generate one in L1 look for similar words in L2 and then see which fits ..and then write and check.

10. S: No, sometimes we don't know other words in Telugu too then we would try to put the idea differently in Telugu itself and then see in English.

Three L1 based strategies seem to emerge when faced by a word problem;

In Excerpt 8; we see strategy 1: generate synonymous L1 words for which an L2 word is not readily available, so generate synonymousL1 words and then look for synonymous L2 words for each of them, assess for appropriateness and then incorporate in the text.

However, in Excerpt 9, the students generate an L1 word for which L2 words are generated, each of them is assessed in the light of the text and then incorporated (strategy 2).

Whereas, in Excerpt 10, we can perceive Strategy 3: in case of difficulty in generating the word in L1, the very idea is modified and then one of the two strategies is applied. In each of the three "strategies", L1 is seen as an evaluating tool at three levels semantic, conceptual and text levels. Each strategy under this category has been also observed in the micro genetic analysis of the collaborative dialogue and documented in Chimirala (2013).

\section{L1 use and L2 Learning: Take-off point for other skills.}

11. Re: only through real writing together, I realized that I can use my LI like this also. Now I know that If we can talk in English then some grammar problems like tense can become easy. That way I think writing also becomes a bit easy. So we should try to write. But that we don't do...

12. S: What Re is saying is correct.... Like that we need more chances to write together, to listen to English and improve our words. I understood that in some ways my Telugu words can also help in understanding and remembering meanings and in using them in writing. I think one helps another... but we don't write like this in Telugu.

Learners felt that focusing on other areas would ease the pressure they experienced while writing. Three pairs felt that if they worked on their 
spoken abilities, as $\mathrm{R}$ says some of the basic structures would be in place so writing would become a 'bit easy'. S, R's partner, had a different observation. She wrote that they were constantly searching for words while writing, so focusing on vocabulary could make writing a lot easier. Both the writers realized that L1 could help in learning and using vocabulary. The learners reflected on their experience of writing to highlight not just areas of improvement but also in what ways their L1 knowledge could help. Notice in excerpt $12, \mathrm{~S}$ pointed out that they did not write collaboratively in their L1 and that they should be have done so.

In sum, the participants of this study showed a positive view of their own L1 use while simultaneously exploring for themselves areas of improvement in L2. Beginning with L1 as the medium of communication, they have realized that their L1 is a social and cognitive tool that can serve more than previously imagined purposes. An examination of the excerpts reveals that exclusive 'pushing' to use the target language need not be the only way to get the learners to notice the 'gaps and holes' in their L2 capabilities. As excerpt 12 indicates, their use of L1 also raised their awareness regarding their L1 capabilities and the need to improve them. The awareness that L1 can help in myriad ways while writing in L2 and in learning L2 can open up new ways of intuitively using their L1.

\section{DISCUSSION}

In this discussion section, we attempt to connect our participants' perceptions to that of the perceptions of learners in the studies we reviewed above. However, before we do so, it must be remarked that, in this study the participants were beginner level writers who had not been taught writing. In the context of the study, the participants clearly attributed their ability to navigate their writing, the act of writing, the act of thinking, negotiating, discussing, and problem solving to L1 and the myriad ways in which they have drew on it. Also, recall that in this study, we like previous studies did not use a forced-option questionnaire as the tool for collecting learner perceptions, rather we used open-ended interviews because in this way we had the opportunity to probe learner thought more deeply. Therefore, one limitation that exists is that the most salient aspects of what the learners reported as significant could have been spoken in the interview. Therefore, with the acknowledgement of the limitations and the context-boundedness of the study, we discuss our learners' perceptions.

One aspect that stands out distinctly is that the participants who engaged in writing, collaborating, and text creation were using the L1 like the teachers' in the classroom space. Al Hinai (2006) lists 11 purposes under which teachers use L1, but the participants went beyond the purposes discussed in 
2.1 by using their intuitive capabilities to not just navigate their writing processes but also to help their partners in very task-specific, contextualized, personally fine-tuned ways of drawing on their L1 for L2 learning and writing. Contrary to Macaro's (1997) high school learners here a teacher's use of L1 was needed for explaining abstract meanings and vocabulary, our study shows the learners realizing simultaneously how their L1 can aid L2 learning and the need to learn specific aspects of L2 such as focusing on vocabulary or listening to English or reading the texts more carefully. In that sense, the participants are beginning to show signs of autonomy and agentive behavior. This finding corroborates Rogoff's theoretical argument of cognitive awareness and growth and Zhou's (2006) argument that learning to know and learning to do are the pillars of learning that propel further learning.

\section{CONCLUSION}

The collaborative writing context has set a natural situation for the learners to use their L1 capabilities and simultaneously benefit from their collaborative attempts to problem solve while writing. One finding that stands apart is that the learners seem to have realized what their focus in L2 learning needs to be, as well as an awareness that their L1 not only supports their L2 learning but in many ways can pave way for it too. The findings of the study suggest that the use of L1 need not be an 'all or none situation' from the teacher's view of L1 use. What matters most is how as teachers we view the other languages the learner arrives with and whether classroom can conceptualize 'allowing' the learners to bank on their bi/multilingual capabilities. A careful examination and introspection of the two questions is mandatory before the question of the usefulness of $\mathrm{L} 1$ is raised. We conclude the paper by pointing out that if learning is what teaching aims at, then 'to use or not to use' is not the question we as teachers should be asking. 


$$
\text { MohanrajEChimirala, Learner Perspective of L1 Use |13 }
$$

\section{REFERENCES}

Al Hinai. (2006). The use of the L1 in the elementary English language classroom.In S. Borg (Ed.). Classroom research in English language teaching in Oman. Muscat: Ministry of Education, Sultanate of Oman.

Al-Nofaie, H. (2010). The attitudes of teachers and students towards using Arabic in EFL classrooms in Saudi public schools. Novitas-ROYAL, $4(1), 64-95$.

Anton, M.\&DeCamilla, F. (1998). Socio-cognitive functions of L1 collaborative interaction in the L2 classroom. Canadian Modern Language Review, 54(3), 314: 353.Auerbach 2000

Atkinson, D. (1987). The mother tongue in the classroom: A neglected source? ELT Journal, 41(4), 241-247

Auerbach, E. (1993). Reexamining English only in the ESL classroom. TESOLQuarterly, 27, (9-32).

Berninger, V., Vaughan, K., Abbott, R., Begay, K., Byrd, K., Curtin, G., Minnich, J. \& Graham, S. (2003). Teaching spelling and composition alone and together: implications for the simple view of writing. Journal of Educational Psychology, 94, 291-304.

Canagarajah, S. (2011).Codemeshing in academic writing: Identifying teachable strategies of translanguaging. The Modern Language Journal, 95(3): 403-417.

Chimirala, U. M. (2013). Exploring L1 mediated lexical searches: Evidence from beginner level writers. Paper Presented at Confluence IV, International Conference on Teaching and Learning English as a Second and Foreign Language, Nagpur, India.

Cook, V. (2001). Using the first language in the classroom. The Canadian Modern Language Review, 57(3), 402-423.

Cummins, J. (2007). Rethinking monolingual instructional strategies in multilingual classrooms. TheCanadian Journal of Applied Linguistics, 10(2), 221-240.

De La Campa\&Nassaji. (2009).The amount, purpose, and reasons for using L1 in L2 classrooms.Foreign Language Annuals, 42(4), 742-759.

De La Collina\& Mayo. (2009). Oral interaction in Task-Based EFL learning: The use of L1 as a cognitive tool. IRAL, 47, 325-345.

Duff, P.\& Polio, C. (1990). How much foreign language is there in the foreign language classroom? The Modern Language Journal,74, 154166. 
14| ELT Worldwide Vol. 1 No. 1

Grosjean, F. (1989).Neurolinguistics, beware! The bilingual is not two monolinguals one person. Brain and Language, 36, 3-15.

Gutiérrez, K. (2000). Teaching and learning in the $21^{\text {st }}$ Century. English education, 32(4), 290-298.

Harbord, J. (1992). The use of the mother tongue in the classroom. ELTJ, 46(4), 350-355.

Hawks, P. (2001). Making distinctions: A discussion of the mother tongue in the foreign language classroom. HwaKang Journalof TEFL, 7, 47-55.

Kobayashi, H. \&Rinnert, C. (2008).Task response and text construction across L1 and L2 writing. Journal of Second Language Writing, 1(1), 7-29.

Krashen, S.D. (1985). The input hypothesis: Issues and implications. London and New York: Longman

Macaro, E.(2001). Analysing student teachers' code switching in foreign language classroom: The Modern Language Journal, 85, 531- 548.

Macaro, E. (1997). Target language, collaborative learning and autonomy. Cleveland, UK: Multilingual Matters.

Mahmoudi, L. (2011). The use of Persian in the EFL classroom: The case of English teaching and learning at Pre-university level in Iran. English Language Teaching, 4(1), 134- 140.

Mohanty, A. K. (2009). Multilingual education in India. SWARA, 1(1), 7.

Murphy, L.\& Roca De Larios, J. (2010).Searching for words: One strategic use of the mother tongue by advanced Spanish EFL writers. Journal of Second Language Writing, 19(2), 61-81.

Nazary, M. (2008). The role of L1 in L2 acquisition: Attitudes of Iranian university students. Novitas-ROYAL, 2(2), 138-153.

Pathak, M. (2005). Using learners' knowledge of L1 as a resource in L2 teaching: An exploratory study. Unpublished M.Phil. (ELT), Central Institute of English and Foreign Languages: Hyderabad

Pennington, M.C. \& So, S. (1993). Comparing writing process and product across two languages: A study of 6 Singaporean university student writers. Journal of Second Language Writing, 2(1), 41-63

Polio \& Duff. (1994). Teacher's language use in university foreign language classrooms: A qualitative analysis of English and target language alternation. Modern Language Journal, 78, 313-326. 
MohanrajEChimirala, Learner Perspective of L1 Use $\mid 15$

Prodromou, L. (2000). From mother tongue to other tongue: What is the place of the students' mother tongue in the EFL classroom? TESOL Greece Newsletter 67. Retrieved March 4, 2004, from http://www.thracenet.gr/bridges/bridges5/

Qi, D.S. (1998). An inquiry into language switching in L2 composing process. The Canadian Modern Language Review, 54(3), 413- 435.

Rogoff, B. (1990). Apprenticeship in thinking: Cognitive development in social context. New York: Oxford University Press.

Rolin-Ianziti\&Varshney. (2009).Student views regarding the use of the first language: An exploratory study in a tertiary context maximizing target languageuse. The Canadian Modern Language Review, 65(2), 249273.

Sasaki, M. (2009). Changes in English as a foreign language students' writing over 3.5 years: A socio-cognitive account. In R. M. Mancho 'n (Ed.), Writing in foreign language contexts: Learning, teaching, and research (pp. 49-76). Bristol: Multilingual Matters.

Scardamalia, M. \&Bereiter, C. (2006). Knowledge building: Theory, pedagogy, and technology. In K. Sawyer (Ed.), Cambridge handbook of the learning sciences (pp. 97-118). New York: Cambridge University Press.

Schoonen, R., Gelderen, A., Glopper, A., Hulstijn, J., Simis, S., Snellings, P., Stevenson, M., (2003). First language and second language writing:The role of linguistic knowledge, speed of processing and metacognitive knowledge.

Schweers, W. Jr. (1999). Using L1 in the L2 classroom. English Teaching Forum, 37(2), 6-7

Sfard, A. (1998). On two metaphors for learning and the dangers of choosing just one. Educational Researcher. 27(3): 4-13.

Storch, N. \&Aldosari, A.(2010). Learner's use of first language (Arabic) in pair work in an EFL class. Language Teaching Research, 14(4), 355375.

Swain,M\&Lapkin, S (1998). Interaction and L2 learning: Two adolescent French students working together. The Modern Language Journal,82(3).

Tang, J. (2002). Using L1 in the English classroom. English Teaching Forum, 40(1).

Wang, L (2003). Switching in first language among writers with differing second language proficiency.Journal of Second Language Writing, 12(4), 347- 375. 
16| ELT Worldwide Vol. 1 No. 1

Wang, W.\& Wen, Q. (2002). L1 use in the L2 composing process: An exploratory study of 16 Chinese EFL writers. Journal of Second Language Writing,11(2), 225-246.

Wells, G. (1998). Using L1 to master L2: A response to Antón and DiCamilla's Socio-cognitive functions of L1 collaborative interaction in the L2 classroom. The Canadian Modern Language Journal,54, 343-53.

Woods. (1993). Critical events in teaching and learning. Falmer Press: London.

Wragg. (1994). An introduction to classroom observation. Routledge: London 